\title{
Indigenous knowledge for seasonal weather and climate forecasting across East Africa
}

\author{
Maren Radeny ${ }^{1}$ (D) Ayal Desalegn ${ }^{2} \cdot$ Drake Mubiru $^{3} \cdot$ Florence Kyazze $^{4}$. \\ Henry Mahoo ${ }^{5} \cdot$ John Recha $^{1} \cdot$ Philip Kimeli $^{6} \cdot$ Dawit Solomon $^{7}$
}

Received: 14 September 2018 / Accepted: 11 June 2019 / Published online: 2 July 2019

(C) The Author(s) 2019

\begin{abstract}
Climate information and agro-advisory services are crucial in helping smallholder farmers and pastoralists in East Africa manage climate-related risks and adapt to climate change. However, significant gaps exist in provision of climate information that effectively addresses the needs of farmers and pastoralists. Most farmers and pastoralists, therefore, rely on indigenous knowledge (IK), where local indicators and experiences are used to observe and forecast weather conditions. While IK-based forecasting is inbuilt and established in many communities in East Africa, coordinated research and systematic documentation of IK for weather forecasting, including accuracy and reliability of IK is largely lacking. This paper documents and synthesizes existing IK for weather forecasting in East Africa using case studies from Ethiopia, Tanzania, and Uganda. The results show that farmers and pastoralists use a combination of meteorological, biological, and astrological indicators to forecast local weather conditions. IK weather forecasting is, therefore, crucial in supporting efforts to improve access to climate information in East Africa, especially in resource-poor and vulnerable communities. The paper draws valuable lessons on how farmers and pastoralists in East Africa use IK weather forecasts for making crop and livestock production decisions and demonstrates that the trust and willingness to apply scientific forecasts by farmers and pastoralists is likely to increase when integrated with IK. Therefore, a systematic documentation of IK, and a framework for integrating IK and scientific weather forecasting from national meteorological agencies can improve accuracy, uptake, and use of weather forecasts.
\end{abstract}

\section{Introduction}

The Fifth Assessment Report of the International Panel on Climate Change (IPCC) shows evidence of increased warming across Africa in recent decades, consistent with anthropogenic climate change, and severely impacting climate-sensitive sectors (IPCC 2014). In East Africa, the anticipated impacts of climate change include increase in frequency and severity of extreme events such as droughts, floods, heavy rain storms, contributing to decline in crop

Maren Radeny

m.radeny@cgiar.org

Extended author information available on the last page of the article 
yields (IPCC 2014). In East Africa, agriculture which employs a large proportion of the population is mainly rainfed and highly vulnerable to climate extremes and change. Availability of reliable climate information services and effective and efficient forecast information dissemination systems are crucial to support decision-making processes across scales.

Advanced knowledge of climate information coupled with agro-advisories enhances capacity of farmers and pastoralists to cope with climate variability and adapt to climate change, and improves management of climate-related risks in agriculture. However, in East Africa, significant gaps still exist in provision of precise, location-specific, timely, and user-friendly climate and seasonal weather forecast information that effectively addresses the needs of farmers and pastoralists. Scientific weather forecasts are often not downscaled and are provided for wider areas and generalized, and thus less effective for farm-level decisions. Moreover, farmers and pastoralists face difficulties in accessing forecasts when they really need to make farming and livestock production decisions. Most farmers and pastoralists, therefore, rely on indigenous knowledge (IK) for seasonal weather forecasts, where local-observed indicators and experiences are used to assess, forecast, and interpret local weather conditions and climate.

Indigenous knowledge has been defined as institutionalized local place-based knowledge rooted in local cultures and has been built upon and often passed on across generations through oral history (Osunade 1994; Orlove et al. 2010). IK is influenced by the previous generations' observations and experimentation, and provides an inherent connection to one's surroundings and environment (Nyong et al. 2007). IK weather forecasting is inbuilt and established in many African cultures and communities, following several years of observations (Ziervogel and Opere 2010), with different indicators used by various communities and cultures to predict future weather conditions. Farmers, pastoralists, and indigenous experts in East Africa observe local weather phenomena and behavior of living organisms (appearances and behavior of certain insects, animals, and plants), direction of wind, and types of clouds to forecast local weather conditions - onset, cessation, intensity and distribution of rainfall and occurrence and magnitude of drought and flood events.

Indeed, previous studies in East Africa indicate that both IK and scientific weather forecasts are used for making crop and livestock production decisions, conserve the environment, and deal with other natural disasters (Ayal et al. 2015; Egeru 2012; Chang'a et al. 2010; Luseno et al. 2003). In rural Tanzania, for example, communities have largely relied on IK to forecast weather through observation and monitoring the behavior of animals, birds, plants, and insects (Kadi et al. 2011; Acharya 2011; Kijazi et al. 2013). In Kenya, agro-pastoralists have IK on indicators of rainfall variability (Speranza et al. 2010). In Malawi and Zimbabwe, communities are combining scientific and indigenous climate forecast information for farm-level decision making and coping with drought (Joshua et al. 2011; Risiro et al. 2012). Hence, IK weather forecasting is crucial in supporting efforts to improve access to climate services in many communities in Africa, especially where meteorological forecasts are absent, or lack reliability, or capacity to interpret meteorological forecasts is limited.

Despite the benefits and significance of IK weather forecasting, lack of systematic documentation is a key challenge. IK is not widely documented and often passed on from one generation to another through oral history, creating a wide inter-generational gap between IK custodians and the young generation. When the old generation who are the main custodians of IK pass away, IK is lost. Other challenges for IK forecasting include lack of coordinated research to investigate IK accuracy, reliability, and uncertainty of IK approaches. In the absence of local specific downscaled scientific forecasts, a systematic documentation and integration of IK in weather forecasting is a promising initiative that needs to be explored. Loss 
of IK threatens the ability of farmers and pastoralists in East Africa to cope with increasing climate variability and adapt to climate change, especially those in remote rural areas. This paper documents and synthesizes existing IK in weather forecasting across East Africa and explores how farmers and pastoralists use IK forecasting for making farming decisions. Specifically, the study strives to draw valuable information on the types and source of climate information, indicators of IK weather and climate forecasting, and reliability of IK weather forecasts compared with meteorological forecasts.

\section{Methods and data}

We use data from three case studies from four different sites across East Africa (Fig. 1), supported by the CGIAR Research Program on Climate Change, Agriculture and Food Security (CCAFS): Borana (Ethiopia), Lushoto (Tanzania) and Hoima and Rakai (Uganda). These sites represent diverse farming systems, ranging from mixed crop-livestock systems to pastoral systems (Table 1).

The case studies used similar mixed research methods. Data were collected through structured household questionnaires, focus group discussions (FGDs), and semistructured interviews with IK local experts and key informants. Households were randomly selected, and information collected from the surveys included demographic characteristics, source of, types of and access to weather information, characteristics of the IK indicators, and perception on reliability of IK. In Hoima and Rakai, additional information collected from the households included whether households use IK to make farming decisions and sources of agricultural information and whether the weather information given out is timely and useful, including other types of climate and weather information households would like to receive.

The FGD participants and key informants were purposively selected through agricultural extension officers and village leaders based on their knowledge of IK and comprised of both men and women. Information collected from FGDs and key informant interviews were similar to that collected at household level, with additional information on signs and interpretation of each IK weather forecasting indicator, precision of IK and community perception on reliability IK weather forecasting, and use of forecast information for agricultural decisions and activities. In Borana, the interviews focused on traditional astrologists, with additional information on duration of each indicator for weather forecasting, and time of observation of the indicators. The traditional astrologists were also asked to illustrate the location of each star in their locality, precision, and accuracy of their forecasting, including factors affecting their weather forecasting practices. Other secondary data sources were also used to complement household data and information from the FGDs and key informant interviews.

In Ethiopia, data were collected from 200 pastoralist households randomly selected from two villages in Borana and complemented with information from four FGDs and key informant interviews with eight traditional astrologists. In Tanzania, data were collected from 77 households randomly selected from seven villages in Lushoto and complemented with information from key informant interviews and FGDs from three of the seven villages. In Uganda, data were collected from 120 households in Hoima and Rakai, randomly selected from six villages, and complemented with information from FGDs. The detailed sampling methods for each case study is described in Ayal et al. (2015), Mubiru et al. (2015), and Mahoo et al. (2015) for Ethiopia, Uganda and Tanzania respectively. 


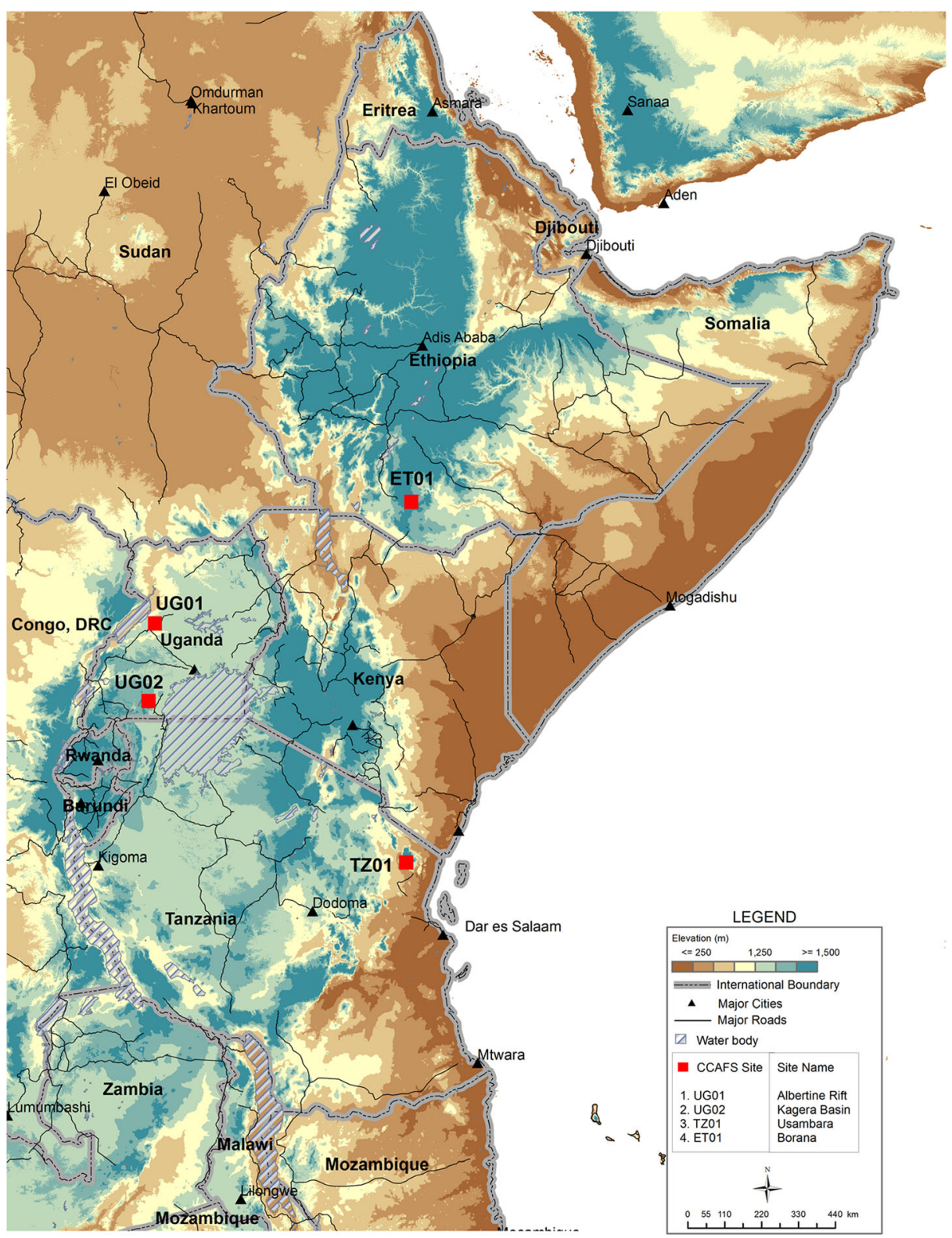

Fig. 1 Map of study sites

\section{Results and discussion}

\subsection{Household characteristics}

Of the 397 households interviewed across the sites, the majority were headed by male, ranging from $68 \%$ in Lushoto to $86 \%$ in Borana. Educational levels and other demographic characteristics varied across the sites. About $80 \%$ of household heads in Hoima, Rakai, and Lushoto 


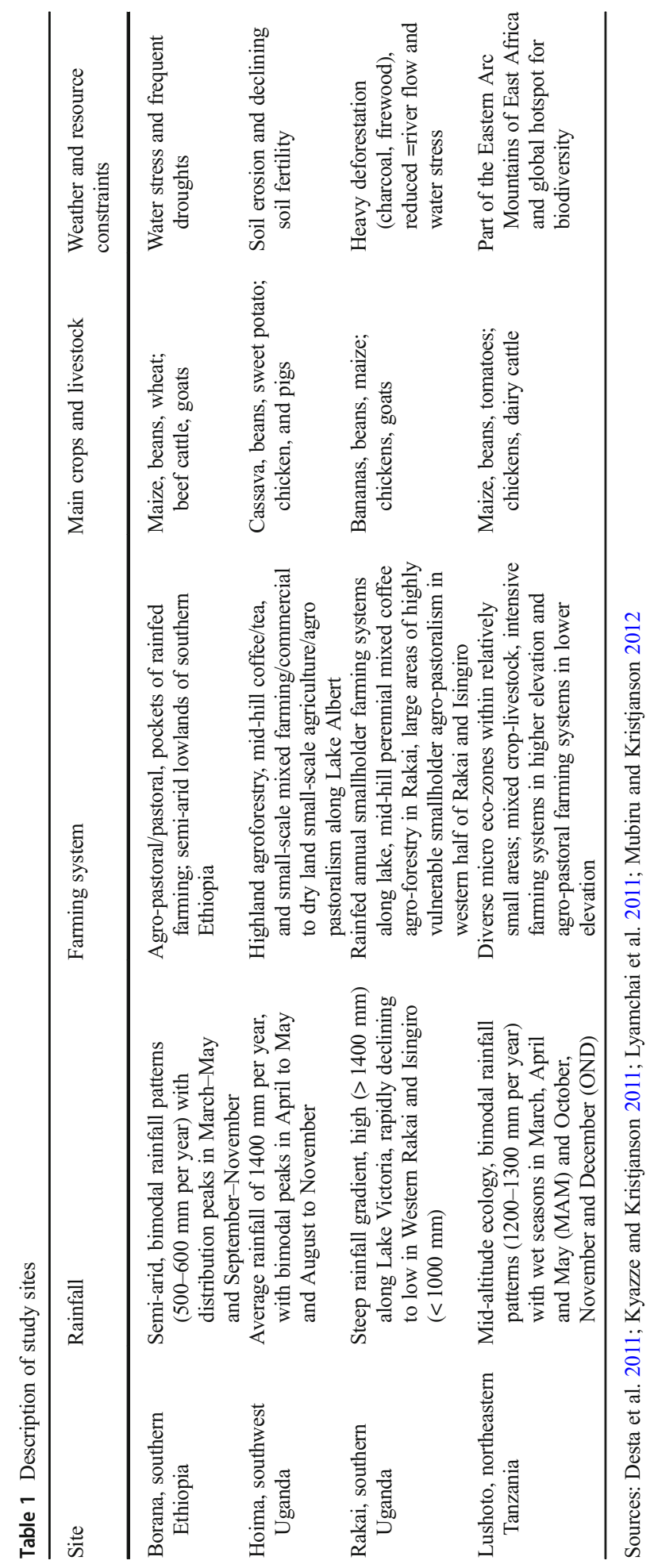


had formal education (primary or secondary level). In Borana, illiteracy levels were very high, with school attendance at primary education at only 3.5\%. Average age of household head in Uganda ranged from 44 in Rakai to 47 years in Hoima. In Borana, the average age of household head was 61 years. In Lushoto, about $46 \%$ of households were over 50 years old, $46 \%$ were between 36 and 50 years, and about $9 \%$ was below 36 years.

\subsection{Source and types of weather information}

\subsubsection{Types of weather information}

Farmers and pastoralists across the sites access different types of weather information that includes onset of rainfall, expected rainfall amount and distribution, duration of cropping season, cessation of rainfall, and severity of weather events (Table 2). The Tanzania Meteorological Agency (TMA), for example, issues various types of climate information, ranging from daily weather forecasts to seasonal forecasts. Onset of rainfall was the most important type of weather information for farmers in Lushoto and Rakai, and pastoralists in Borana. In Hoima, the expected rainfall amount was the most important information for farmers. Drought occurrence and severity of weather events were equally important for pastoralists in Borana (Table 2). While most farmers have access to weather information, they also seek more detailed information on (i) amounts, intensity, duration of rainfall and guidance on what to plant; (ii) onset of drought, duration, and what to do including information on drought resistant and early maturing crop varieties; and (iii) severity of the sun, drought and rainfall forecast to take appropriate farm-level decisions.

\subsubsection{Source of weather information}

Farmers and pastoralists received weather information from different sources: media, indigenous sources, relatives, friends, neighbors, village and clan meetings, service providers, and others (Table 3). In Borana, Ethiopia, IK weather forecasting is the main source of weather information (97\%), largely attributed to limited access to scientific weather forecasts. Forecast information is disseminated directly from IK experts or indirectly through clan or village meetings, relatives, and friends. Similarly, in Lushoto, Tanzania, the majority of households accessed weather information from indigenous sources (68\%), as TMA forecasts are sometimes issued late after farmers have already made decisions. In Hoima, Uganda,

Table 2 Type of weather information accessed by farmers and pastoralists

\begin{tabular}{lllll}
\hline Weather information $(\%)$ & Borana & Hoima & Rakai & Lushoto \\
\hline Amount of rainfall & 96.2 & 84.7 & 58.9 & 26.0 \\
Onset of rainfall & 98.2 & 23.7 & 82.1 & 55.8 \\
Rainfall distribution & 61.4 & 23.7 & 39.3 & - \\
Cessation of rainfall & 57.3 & 1.7 & 14.3 & 32.5 \\
Duration of cropping/rainy season & 3.0 & 3.4 & 42.9 & 26.0 \\
Drought occurrence & 93.0 & - & - & 28.6 \\
Severity of weather events & 87.0 & 1.7 & - & 15.0 \\
Strong winds occurrence & - & - & - & 11.7 \\
Floods & - & - & 60 & 77 \\
$\mathrm{~N}$ & 200 & 60 & & \\
\hline
\end{tabular}


Table 3 Sources of weather information

\begin{tabular}{llllr}
\hline Source of information $(\%)$ & Borana & Hoima & Rakai & Lushoto \\
\hline Radio & 10.5 & 46.9 & 76.3 & 61.0 \\
Relatives, neighbors, and friends & 93.0 & 59.2 & 44.1 & 24.7 \\
NGOs, researchers, and extension agents & 26.0 & 44.9 & 18.6 & 7.7 \\
Indigenous sources & 96.5 & - & - & 67.5 \\
Village/clan meetings & 85.0 & - & - & 27.8 \\
Newspapers and television & - & - & 60 & 14.3 \\
$\mathrm{~N}$ & 200 & 60 & & 77 \\
\hline
\end{tabular}

findings from FGDs showed that the majority of farmers rely on IK weather information from elders. Most households trust IK weather information from elders, as they believe it is based on experience; besides, their respect for elders ensures easy uptake.

Exchanges with other farmers were identified as the most cost-effective source of weather information, with reliability depending on the interpretation of the person who receives the information first. Village meetings were also important sources of weather information in Lushoto. In Hoima, the agricultural extension system was ranked as a reliable channel for disseminating weather information. Findings from the FGDs across the sites show that weather information from radio is often well-summarized and usually broadcasted in local languages that increases understanding by farmers and pastoralists. Although weather information from print media such as newspapers was detailed, they are only meaningful and useful for literate people in these communities.

The findings above on types and sources of weather information are similar with those from previous studies in these sites (see Desta et al. 2011; Lyamchai et al. 2011; Kyazze and Kristjanson 2011). In Borana, for example, about half of the households received some form of weather forecast information regarding extreme events, and almost three-quarters reported getting weather-related information from traditional sources (Desta et al. 2011). Similarly, Luseno et al. (2003) found that indigenous forecasts were widely heard among pastoralists in Southern Ethiopia and Northern Kenya. Also in Lushoto, Tanzania, the radio was the most common source of information (Lyamchai et al. 2011), with almost three-quarters of the households owning a radio and thus making it a useful media for accessing climate information. Households also relied heavily on friends and relatives, and their own observation for weather forecasting in the short and long run. Traditional sources and IK were used by some households for forecasts of extreme weather events and timing of onset of rains.

Similarly, in Hoima and Rakai in Uganda, the radio emerged as the main source of agricultural information, largely attributed to a proliferation of FM radio stations across Uganda, resulting in a wide radio coverage. Between 2004 and 2008, there was nearly a 50\% increase in the number of privately owned FM radio stations, with about 250 private FM radio stations between 2012 and 2014 (UBOS 2015). The radio stations also broadcast agricultural awareness programs in local languages; thus, the information can be easily understood by many people at the local level. In Rakai, for example, the radio was reported as the most efficient and reliable channel which can be used to disseminate timely weather information to farmers. Farmer-to-farmer information exchange also ranked highly across the Uganda sites, mainly attributed to the set-up of rural communities in Uganda, where the local culture encourages sharing of information related to livelihoods such as agriculture. There is also great potential to improve access and dissemination of climate and seasonal weather information through other new emerging channels such as NGOs, agricultural input suppliers, religious organizations and gatherings, including schools. 


\subsection{Indigenous knowledge weather and climate forecasting}

Farmers and pastoralists in East Africa use a combination of plants, animals, insects, meteorological, and astrological indicators to assess and predict local weather conditions (Egeru 2012; Acharya 2011; Chang'a et al. 2010). In this paper, we group IK indicators into three main categories: meteorological, astrological, and biological.

\subsubsection{Meteorological indicators}

Different meteorological indicators were used. In Hoima and Rakai, clouds have always been associated with rain and there is an old local proverb "a ring around the sun or moon brings rain upon you soon." Two well-known rain clouds - nimbostratus (dark, rain carrying cloud of bad weather) and cumulonimbus (cloud that produces showers and thunderstorms)-are used for forecasting in Uganda. Appearance of these clouds indicates a high probability of rainfall. Indigenous meteorological indicators used to predict onset of rains in Hoima and Rakai included appearance of dark clouds, direction and strength of wind, very high night temperatures, lightning and thunder at night with no rain, and appearance of less dew on grass and plants (Table 4). In both sites, appearance of dark clouds was rated as the best meteorological indicator to predict onset of rainfall.

Slightly different meteorological indicators were reported in Lushoto (Table 4). More than $70 \%$ of households identified high temperatures as the best indicator for predicting onset of rainfall. Excessive heat and warming towards end of the dry season indicates a higher likelihood of above normal rainfall, while high temperatures during the night indicate a likelihood of rainfall the next day. Strong and swirl winds indicate an imminent rainfall onset, while repeated lightning in the evening during dry season is an indication of onset of short-rain season, locally known as vuli.

Smallholder farmers and pastoralists also have specific meteorological indicators for cessation of rainfall. In Uganda, meteorological indicators of rainfall cessation included appearance of a lot of mist in the morning and at night, a very clear sky, very cold mornings and evenings, more frequent drizzles and hot nights (Fig. 2). On average, farmers had knowledge of about six indicators, with at least four of these indicators being used to make agricultural production decisions. Other meteorological indicators of rainfall cessation included high frequency of lightning when it rains, high incidences of lightning strikes, and mild temperatures during day time. For each indicator of rainfall cessation, there was at least a farmer making critical production changes and decisions regarding planting, preparing storage facilities, and postharvest handling, including exploring market opportunities for their produce.

Table 4 Meteorological indicators used to predict onset of rainfall in Uganda and Tanzania

\begin{tabular}{|c|c|c|c|}
\hline Meteorological indicators $(\%)$ & Hoima & Rakai & Lushoto \\
\hline Appearance of dark clouds & 100 & 91.7 & \\
\hline Direction and strength of wind & 95.0 & 80.0 & 35.1 \\
\hline High temperatures & 85.0 & 91.7 & 74.0 \\
\hline Lightning and thunder with no rain & 73.3 & 81.7 & 57.0 \\
\hline Less dew on grass/plants & 21.7 & 38.3 & \\
\hline Appearance of white clouds in the evening & & & 15.6 \\
\hline High humidity and temperature & & & 9.1 \\
\hline $\mathrm{N}$ & 60 & 60 & 77 \\
\hline
\end{tabular}




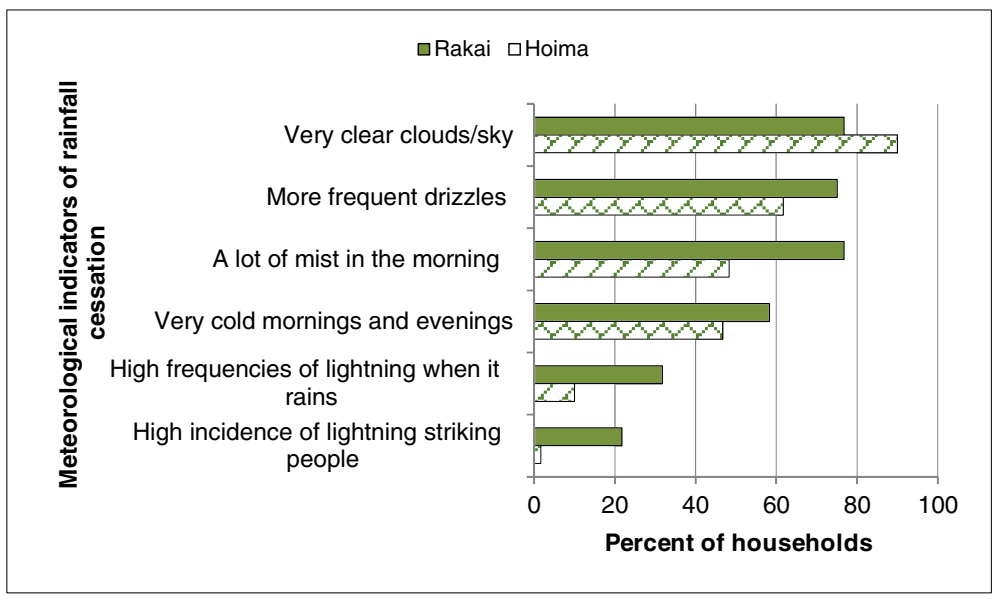

Fig. 2 Meteorological indicators for predicting cessation of rainfall in Hoima and Rakai, Uganda

In Borana, Ethiopia, meteorological indicators used for forecasting the timing and distribution of rainfall include condition of the sun, cloud cover, and wind direction (Fig. 3), often to strengthen astrological weather forecasting. If, at the time of star observation, the sun is surrounded with what is locally called Muna Garti, traditional experts conclude that drought will occur in the next season. If, on the same day, a solar radiant with reddish color is observed at sunrise, indigenous experts believe the next season will have normal rainfall. A dull and white sky at sunrise and a strong wind blowing from east to west are all signs of drought. However, if the wind blows slowly with dust rising upwards, a normal rainfall season is expected at the right time in terms of the onset. Appearance of a whitish feather-like column of cloud (in a vertical position) in the sky is believed to be indicative of rainfall onset within a short period.

\subsubsection{Biological indicators}

Biological indicators used across East Africa for weather forecasting can be further disaggregated into animal and plant indicators. Changes in animal behavior at the onset of rains are believed to

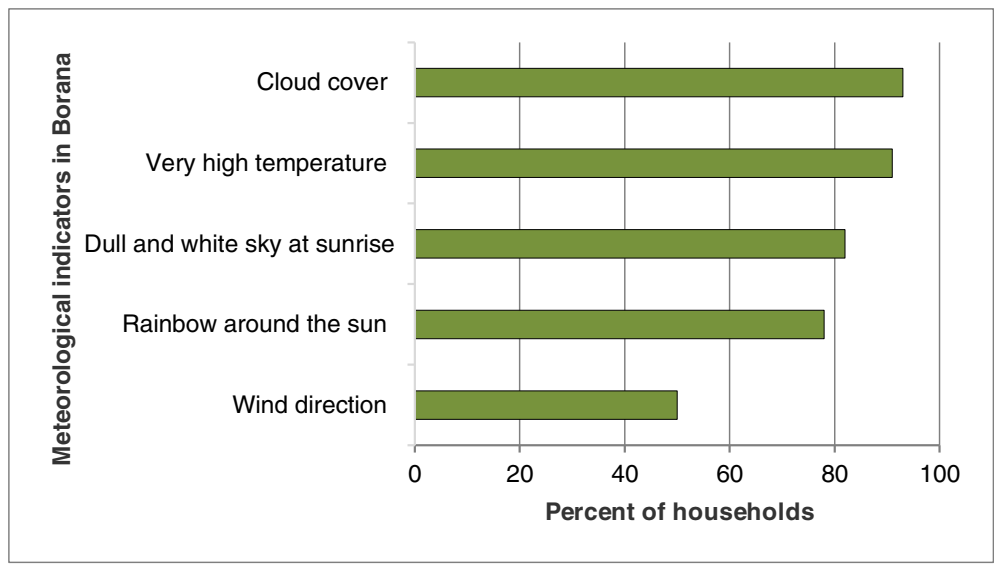

Fig. 3 Meteorological indicators for forecasting timing and distribution of rainfall in Borana, Ethiopia 
be triggered by aroma from volatile compounds that increase in intensity when changes occur in humidity (Galacgac and Balicasan 2009). Increasing air pressure due to upcoming rainfall is another biological factor that might trigger behavioral changes in animals. In Uganda, croaking of frogs during the day (as cited 68\% of households in Rakai and $43 \%$ in Hoima) and singing by some specific birds are widely used to predict likelihood of rainfall onset. Frogs emerge and croak to cope with the humid air caused by rain. For rainfall cessation, the noise made by certain insects was the main animal indicator used as reported by $53 \%$ of households in Rakai. Other less known animal indicators included noise made by birds and prevalence of mosquitoes. Their movements in the sky, arrival and disappearance, and certain sounds and cries are believed to communicate the type and characteristic of upcoming weather.

In Lushoto, Tanzania, biological indicators based on animal behavior included birds, insects, and some large animals. The behavior, appearance, and movement of some birds are frequently used to predict seasonal weather. Monitoring of the behavior of these birds is done informally, and with time and experience, the local people have come to realize the distinct and unique features of some of the birds. Occurrence of large flocks of swallows and swans roaming from the South to North during the months of September-November, for example, is an indication of onset of short rain sometimes within two to three days. Other birds used include caucal, ducks, wild bird, and Golden Oriole (Fig. 4). Coucal singing out loud is an indication of short rains, while sighting of an owl in the sky means it is planting season. Ducks stretching their wings and playing in the dust is a sign of rainfall onset, especially the short rains. Similarly, chicken stretching their wings repeatedly are a sign of onset of short rains. Wild bird singing out loud and flocks of hornbills and Fischer's lovebird crying are all indicators of short rains. Similarly, Golden Oriole singing out loud is an indication of a good rainfall season. Wild bird walking to the valley or wetlands indicates short rains, while the presence of the Yellow bird is an indication of the long rains (masika).

Appearance of wild animals within the community and behavior of domestic animals are also used in Lushoto to predict weather and climate. Baboons, monkeys, leopards, and antelopes coming into the village during dry season is an indicator of good rains in the coming season. Goats, sheep, and cattle flapping their ears repeatedly at any time during the dry season indicates near onset of rains, and prospects of a good season. Various insects are also commonly used to predict

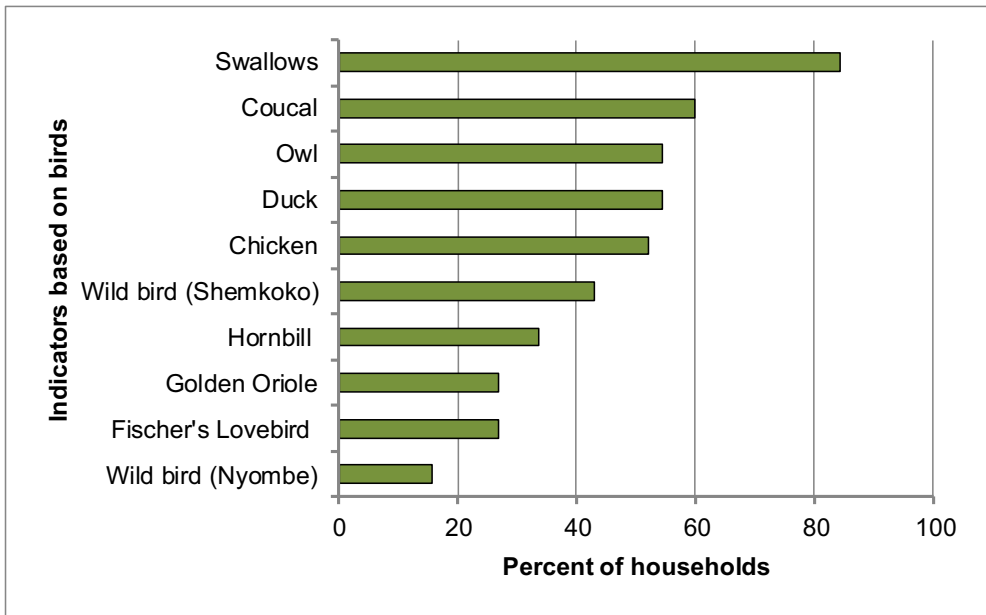

Fig. 4 Biological indicators based on birds in Lushoto, Tanzania 
weather and climate in Lushoto and include army ants, odontotermes, butterflies, and frogs. Large numbers of army ants occurring almost everywhere, including within houses and appear to be "celebrating" is an indication of onset of mostly heavy rains during short-rain season. Presence of insects on Albizia trees with water dripping from them is an indication of a good season, almost a month before start of short rains. Occurrence and migration specifically of the black butterflies from south to north is an indication of early onset of rains and a prospect of a good season.

Occurrence of flying ants (Odentotermes spp.) after strong sunshine indicates proper rains have started, sufficient for planting for the short and long seasons, with adequate soil moisture. Appearance of green grasshoppers in large numbers in the fields indicates onset of short-rain season. Frogs starting to make a lot of noise is an indication of rainfall onset, and the louder the noise signifies a good season. Occurrence of shelled or garden snail in large numbers especially at the time when they are not expected is an indicator of onset of short-rain season and a prospect of a good season. Bees appearing in big groups and appearance of locusts in large numbers are also indicators of onset of long rains.

In Borana, Ethiopia, specific body conditions and behaviors of animals are used to predict future weather conditions and are described in detail in Ayal et al. (2015). Drought indicators related to behavior of cattle include calmness and sleeping very close to one another in the pen, refusing to go and graze in nearby pasture, preference for staying near watering points, loss of appetite for grass and salt, lack of interest in reproductive activities, and isolation from the rest of the herd for bulls. Other drought related indicators for cattle include weight loss with standing hair on skin, defecating and urinating in a sitting position, and with unusually reduced amounts of cow dung. For a normal rainy season, indicators related to cattle body condition and behavior include licking of each other's body, display of a relaxed mood and getting away from water points after drinking, normal reproductive behavior (including increased activity in bulls). In the absence of sickness, these body conditions and behaviors reflect future weather conditions.

Wild animals and insects are also used for weather forecasting in Borana. If a ground squirrel is busy digging holes, a normal rainy season is expected. An army of ants moving along in a nearly straight line indicates normal rainfall season, while if they are dispersed in search of food it signifies the likelihood of drought. Migration of bees during season of resource abundance from north to south is also a sign of drought, while migration in the reverse direction indicates a normal rainfall season.

Certain plants and trees are more sensitive to changes in atmospheric conditions than others. In Hoima and Rakai, Uganda, about $60 \%$ of the households reported flowering of specific trees as indicative of the onset of the rainy season. Well-known plant indicators for weather forecasting include the sprouting of young shoots of Milicia excelsa tree (locally known as Mvule) and blooming in coffee. About $30 \%$ of the households reported the sprouting of young shoots of Mvule often indicates onset of rainy season, while shedding of old leaves indicates the beginning of dry season. These phenological changes in plants are triggered by changes in humidity associated with the beginning of the rainy or dry season.

In Lushoto, commonly used plant indicators included flowering of vernonia, pears, Albizia, and plums. Heavy flowering of fruit trees like pears are a good indicator of the rainy season. When vernonia, tree starts to flower it is considered to be a sign of early onset of rainfall. Flowering and generation of new leaves of the baobab/fig tree indicates rainfall onset and prospects of the long rains. Shedding of leaves of black nightshade, and abundant fruit production and dropping of leaves of the datura plant are also indicators of rainfall onset. But when datura leaves turn upside down, it is an indication that the season is going to be too cold, and destructive to crops. Appearance of insects locally known as vidododo on an Albizia tree with water dripping from the trees during a 
dry season is an indication of onset of short-rain seasons. A pigeon pea plant producing a lot of flowers than normal is an indication of a good season. Other plant indicators of rainfall onset and good season included flowering of loquarts, excessive flowering of coffee trees (short-rains), and many buds and flowers for avocado trees.

In Borana, Ethiopia, flowering patterns of Acacia tortilis and aloe tree are used for seasonal weather forecasting, with rainfall often expected a month after flowering of these trees. In contrast, a drought season is expected if these trees bloom small amounts of flowers and shed more quickly than under normal circumstances. When plants of Commiphora africana (Hamesa), Commiphora erythraea (Agarsu), Boswellia neglecta (Dakkara), and Delonix elata (Sukela) sprout lavish green leaves in the month of August, a normal short-rain season is expected, and if this occurs in January, it is an indication of a normal long-rain season. Otherwise, a drought will be forecasted for the next season. For a more accurate weather forecast, the Bisduga plant (Kirkia burgeri) is preferred but the observed physical conditions and corresponding interpretations are similar with the other plant types.

\subsubsection{Astrological indicators}

Astrological indicators were more pronounced among the Borana pastoralists in Ethiopia, with a range of indicators used for weather forecasting: interpreting alignment of the moon and stars, size and appearance of the star, and appearance and form of cloud cover. Traditional astrologists in Borana (Urgin Elaltus) use seven stars (Lami) individually or in combination locally known as Busan, Soresa, Algajama, Arba-Gadu, Walla, and Bassa - that are believed to be important for forecasting. Based on star-moon alignment, traditional astrologists can forecast the timing, duration, and amount of rainfall or drought up to 6 months or years in advance.

Traditional astrologists use the 12 months of the lunar Borana calendar to choose when to observe the star-moon alignment. For climate and weather forecasting, the 12 months are grouped into two (of 6 months). The first group comprises of Birra, Ciqqa'a, Sadassad (representing short-rain season), Abrassa, Amagiid, and Gurandhala (representing hot dry season). For forecasting, the star-moon alignment is observed only during Birra (September) between the 14 and 15 day of the moon at about 9:00 pm. The second group comprises of Biouttessa, Chamissa, Buufa (representing long-rain season), Waxxabaji, Obora-Gudda, and Obra-Teka (representing cold dry season). For forecasting, the star-moon alignment is observed during Biouttessa (March), 1-2 day of the moon at 09:00 pm. However, there is no clear justification why the traditional astrologists choose these two particular months. Figure 5

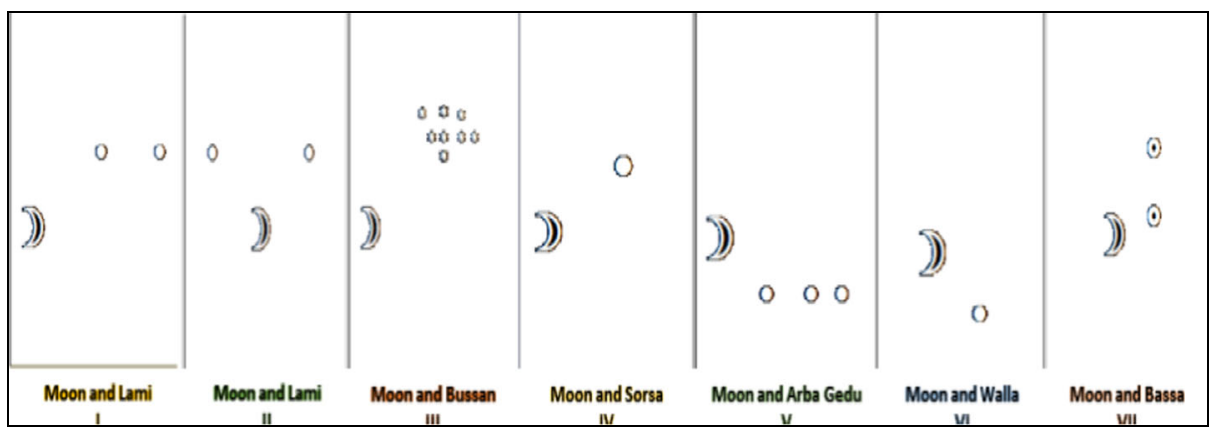

Fig. 5 Seven moon-star alignments for forecasting in Borana 
shows seven possible star-moon alignments that occur in the months of Birra and Biouttessa, with each alignment interpreted by the Urgin Elaltus for different weather forecasts.

The first star-moon alignment, observed during the month of Birra, shows that 14 days have passed since the first appearance of the moon and indicates a late onset and early cessation of the next long-rain season. If the first star-moon alignment is observed during the month of Biouttessa, then, a drought and famine are expected during the short-rain season. Observation of the second star-moon alignment (Gobana) indicates the next long-rain season would be normal. Observation of the second moon-star alignment during the month of Biouttessa indicates a timely and optimal rainfall in the next season.

The geometrical alignment of the moon with the Busan star is also used for weather forecasting. The Busan observed in the west to a man milking a cow in the evening at about 08:00 pm under the belly of the cow indicates onset of the long-rain season. However, Busan is observed in the east under similar circumstances, indicates onset of the short-rain season. However, it is not clear why the observer should be in a milking position in order to observe Busan in the east and west. It is important to recognize that these observations are made while members of the community undertake their daily routines and use these observations to forecast the onset of long-rain and short-rain seasons.

Movement of the morning star-locally known as Bekalcha Bari (East direction) and Bekalcha Gulchu or Ahiha (in the West) - is an important indicator used to forecast extreme drought in Borana, Ethiopia. Appearance of the star in the West 70 days after its appearance in the East, and if it appears in the East 7 days after its appearance in the West, indicates normal rainfall in the next season. In contrast, if the star is not seen in the East on the seventh day of its appearance in the West, and is observed again in the West after 140 days, is an indicator of extreme drought in the future.

The position of a star-locally known as Kormi Mado - is used to forecast rainy seasons. The star is in the southern hemisphere and moves in a clockwise direction and never moves to the north of the perceived equator line (Fig. 6). Forecasting is based on the size of the star at

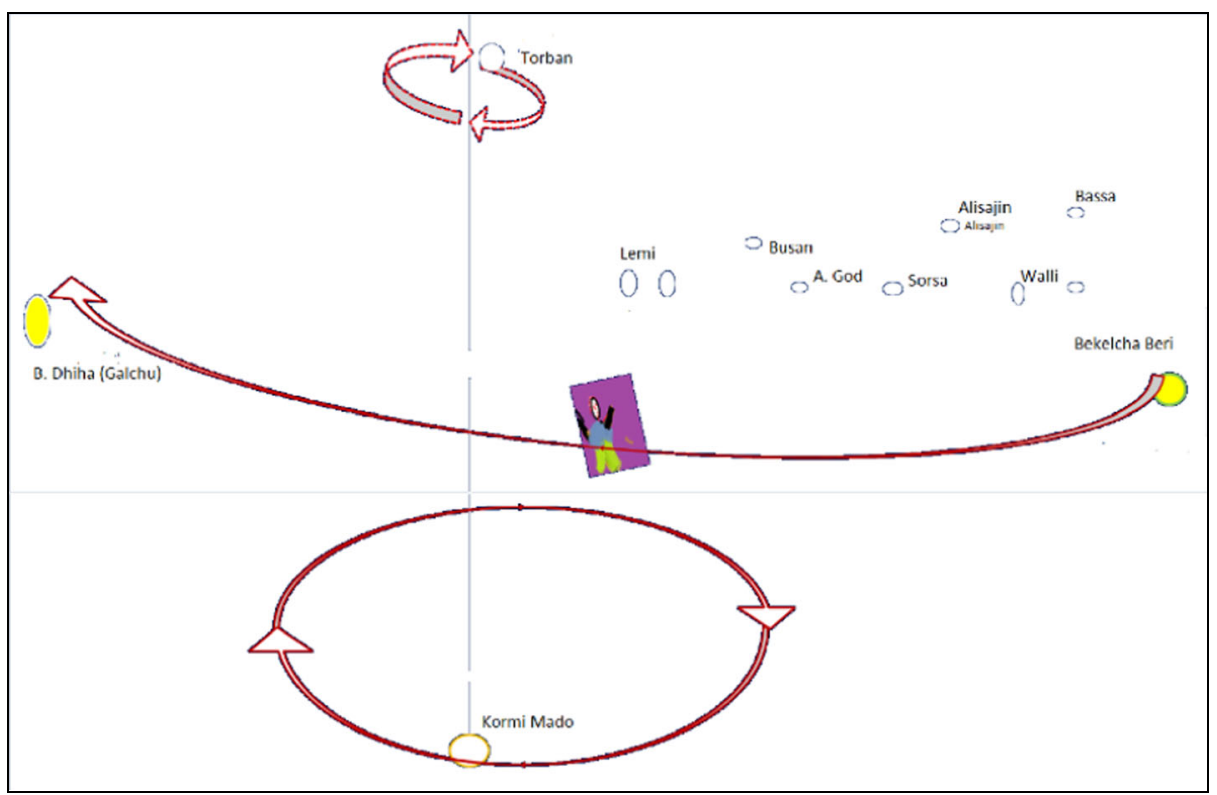

Fig. 6 Important moon positions used for climate forecasting in Borana 
the time of observation. A seemingly smaller star observed in the month of Birra on the 14th day of the moon at 09:00 pm local time is an indication of drought in upcoming long-rain season. In contrast, if the star is bigger in size and observed on the same month, day, and time, then a normal rainy season is expected. Interpretation of the size of the star is the same; for short-rain season, however, the timing of observation is in the month of Biouttessa, on the first day of the moon and 09:00 pm local time.

Turban is located only in the northern hemisphere of Borana moving in a clockwise direction. Position of Turban is used to forecast short-rain and long-rain seasons. When observed in the position shown in Fig. 6, traditional experts reported that this indicates the rainy season is approaching. When Turban is observed near the extreme North Pole, then short-rain season is approaching. Conversely, when Turban moves from its southern path into the northern path of rotation, it is believed that the long-rain season is approaching.

In Lushoto, Tanzania, the occurrence of a halo moon (moon surrounded by a yellow ring), moon with different colors like rainbow, and appearance of moon in a circular shape (normal) are all indicators of onset of rains for long-rain and short-rain seasons. Moon surrounded with heavy clouds is a sign of a good rainfall season. Also, the moon orientation can be used to predict a drought season. A slanted position of the moon crescent is an indicator of a drought season, with less rain expected on the inclined side. The north-south wind direction in September is believed to be a sign of onset of short-rain season and heavy rainfall in the upcoming season. Frequent and persistent winds indicate that it will rain within a week, while wind blowing without drying vegetation and soil is also an indication of rains. Strong winds and a red moon are all indicators of onset of a short-rain season, sun heating without wind indicates onset of rains, and white moon indicates the onset of rain for the long-rain season.

Similarly, in Uganda, about $70 \%$ of households in Rakai and almost half (48\%) in Hoima reported positioning of the moon as an indicator of rainfall onset. Starry nights are a sign of rainfall cessation, with about $41 \%$ of households across the two sites reporting appearance of many stars in the sky at night as an indication of rainfall cessation. Some of the meteorological and astrological indicators of rainfall cessation are interrelated. Very clear skies devoid of clouds especially at night lead to a starry night and traditional cooling, which in turn leads to cold nights and mornings as well as the condensation of air, resulting in mist or fog at night and in the morning (Moran and Morgan 1997).

\subsubsection{Other indigenous indicators}

Changes in the human body are at times used to predict weather and climate in Lushoto, Tanzania. Palpitation on top of the right eye and one-sided headaches, for example, are also considered an indication of onset of rains. Too much heat and humidity indicate imminent rainfall. Other traditional indicators of a drought season in Lushoto included excessive flowering of mango trees and peaches. Birth trends are also used to predict weather or season. For example, a high birth rate of male children and animals in a particular season is usually taken as a sign of a likely drought season.

\subsection{Reliability and use of weather forecast information}

Figure 7 shows the perceived reliability of the IK seasonal weather forecasts as compared with scientific forecasts in Lushoto, Tanzania. More than half of the farmers $(56 \%)$ believed that the IK forecasts were reliable compared with $22 \%$ for scientific forecasting. Very few farmers 


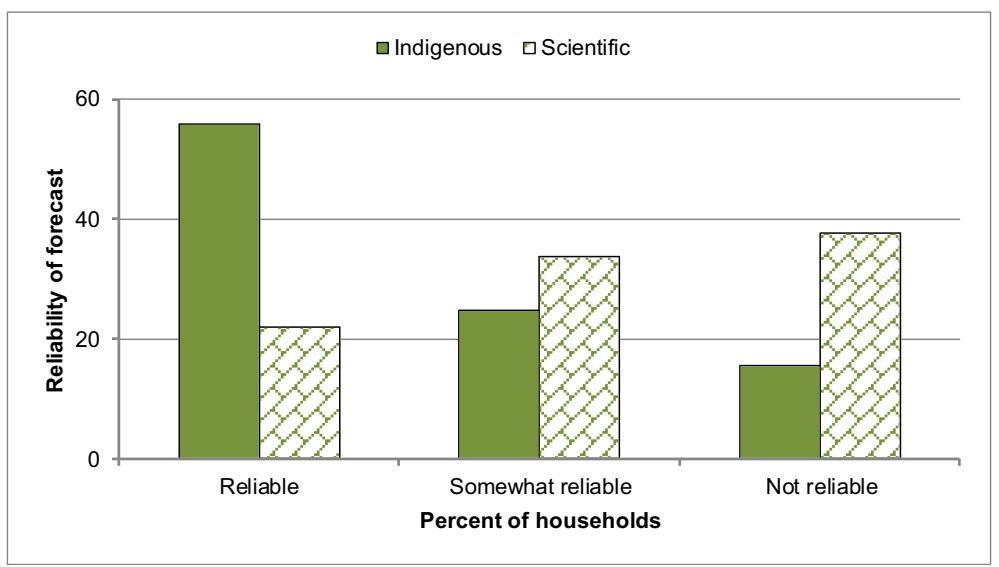

Fig. 7 Reliability of scientific and IK weather forecast information in Lushoto, Tanzania

(16\%) thought IK forecasts were not reliable, as compared with $38 \%$ for scientific forecasts. In 2012, for example, comparison of the seasonal March-April-May (MAM) forecasts from IK and TMA in Lushoto showed both approaches predicting a normal rainfall season. The IK forecasts were, however, more reliable in the long-rain (MAM) season compared with the short-rain season (October-November-December).

Over $90 \%$ of the respondents in Lushoto, Tanzania, indicated that they were aware of the indigenous weather forecasts, with $83 \%$ reporting using IK forecasts to plan their agricultural activities. Three local IK forecasting groups representing different agro-ecologies have been formed in Lushoto. Every 3 months, these groups meet with experts from TMA to compare IK forecasts with seasonal outlook forecasts from TMA. The forecasts are then integrated and packaged for dissemination. In Borana, Ethiopia, climate forecast based on star-moon alignment is considered the most effective and reliable indicator for IK weather forecasting with pastoralists using IK forecasts to plan livestock mobility and sharing among relatives to minimize drought losses. In Hoima and Rakai, Uganda, some farmers use IK indicators to make important production decisions that enable them to cope with climate change. These decisions include timing of land preparation, dry planting, purchase of seeds for planting, type of crops to grow, type of agronomic practices to use, and planning for labor redistribution and allocation.

These results are consistent with those of Luseno et al. (2003), where pastoralist in southern Ethiopia and northern Kenya expressed considerable confidence in indigenous climate forecasts with regard to onset of rainfall (94\%) and amount of rainfall (84\%), and a majority had at least some confidence in forecasts of both cessation of rainfall and rainfall amounts in other areas. In Eastern Kenya, Speranza et al. (2010) found that agro-pastoralist believe in IK efficacy and rely on IK, but also consult additional sources with IK forming a basic knowledge frame within which agro-pastoralist position and interpret meteorological forecasts. In Southern Malawi, Joshua et al. (2011) found that IK forecasts were regarded to be more accurate than scientific forecasts, and farmers relied on IK to make decisions on land preparation, crop selection, planting, weeding, harvesting, storage, and processing of food. The high level of confidence in IK expressed by the local communities in these East African countries could be explained by various reasons. First, scientific forecasts are made at very low spatial resolution, while indigenous forecasts tend to be very local in focus. Second, IK 
forecasts are mostly derived from local experiences and communicated in local languages, and typically by "IK experts" known and trusted by the communities. Other reasons include simplicity, familiarity, ease of understanding, and in-built nature of IK as compared with the complex and at times the difficult to understand and probabilistic nature of scientific forecasts. However, increased climate variability and climate change will potentially affect the accuracy and reliability of IK forecasting (Risiro et al. 2012; Joshua et al. 2011; Chang'a et al. 2010), underlining the need for an integrated approach in weather forecasting.

\section{Conclusions}

Climate in East Africa is changing and severely affecting agriculture, which is mainly rainfed and thus highly vulnerable to climate variability and change. Advanced knowledge of climate and weather information, coupled with agro-advisory services, has great potential to enhance capacity of farmers and pastoralists in East Africa to cope with climate variability and adapt to climate change, including improving management of climate-related risks in agriculture. Reliable climate information services, effective and efficient forecast information, and dissemination systems are crucial to inform on-farm decision making. Scientific seasonal weather forecasts provided by national meteorological agencies are often not downscaled and are provided for wide areas and generalized, thus less effective in addressing the needs of farmers and pastoralists. Indigenous knowledge fills this important gap for making crop and livestock production decisions, conserving the environment, and dealing with other natural disasters. This paper documented and synthesized existing IK in weather forecasting in East Africa and explored how farmers and pastoralists use IK forecasting for making farming decisions using case studies from Ethiopia, Tanzania, and Uganda.

The results show that farmers and pastoralists across East Africa use a combination of meteorological, biological, and astrological IK indicators to forecast seasonal weather conditions and make important crop and livestock production decisions. IK plays a key role in supporting local efforts to forecast and make sense of seasonal climate variability, especially in the absence of downscaled location-specific forecasts. Biological IK indicators included specific plants and animals and were more variable compared with meteorological and astrological IK indicators. Astrological IK indicators were more pronounced in Borana, with pastoralists using the IK forecasts to plan livestock mobility and sharing among relatives and friends to minimize drought losses. The pastoralists in Borana, Ethiopia, and farmers in Lushoto, Tanzania, considered IK forecasting a reliable source of climate and weather information. Certain IK indicators were considered more effective and reliable than others. In Borana, for example, the star-moon alignment is the most reliable IK indicator, while cloud color is the preferred indicator in Hoima and Rakai (Uganda).

The challenges facing IK weather forecasting include poor knowledge transfer system, insufficient documentation, death of forecast experts, and influence of religion and modern education. Other factors threatening IK weather forecasting include extinction of some plants and animals, desertification in pastoral areas, destruction of vegetation resulting from rapid urbanization and high population growth; all of which affect the biological IK forecasting indicators. Progressive loss of IK thus threatens ability of farmers and pastoralists, especially in rural and remote vulnerable areas in East Africa, to cope with climate variability and adapt to climate change. Therefore, a systematic documentation of IK is essential, including developing curricula on traditional weather forecasting at appropriate levels. The challenge ahead is 
finding ways of integrating IK forecasting with scientific forecasting to improve the accuracy of climate and seasonal weather forecasts, which is likely to increase trust and willingness of farmers and pastoralists in East Africa to use scientific forecasts. Further in-depth analysis is needed in order to understand how the IK indicators are used for forecasting and the context in which the indicators are used, including investigating the accuracy, reliability, and validity of IK indicators for weather and climate forecasting.

Acknowledgements This work was implemented as part of the CGIAR Research Program on Climate Change, Agriculture and Food Security (CCAFS), which is carried out with support from CGIAR Trust Fund Donors and through bilateral funding agreements. For details, please visit https://ccafs.cgiar.org/donors. The views expressed in this document cannot be taken to reflect the official opinions of these organizations.

Open Access This article is distributed under the terms of the Creative Commons Attribution 4.0 International License (http://creativecommons.org/licenses/by/4.0/), which permits unrestricted use, distribution, and reproduction in any medium, provided you give appropriate credit to the original author(s) and the source, provide a link to the Creative Commons license, and indicate if changes were made.

\section{References}

Acharya S (2011) Prediction of rainfall variation through flowering phenology of night-flowering jasmine (Nyctanthesarbor-tristis L.Verbenaceae) in Tripura. Indian J Tradit Knowl 10(1):96-101

Ayal DY, Desta S, Gebru G, Kinyangi J, Recha J, Radeny M (2015) Opportunities and challenges of indigenous biotic weather forecasting among the Borena herders of southern Ethiopia. SpringerPlus (2015) 4:617

Chang'a L, Yanda P, Ngana J (2010) Indigenous knowledge in seasonal rainfall prediction in Tanzania: a case of the South-Western Highland of Tanzania. J Geogr Reg Plann 3(4):66-72

Desta S, Tezera S, Gebru G, Kristjanson P (2011) Summary of baseline household survey results: Borana, Ethiopia. In: CGIAR research program on climate change, agriculture and food security (CCAFS). Copenhagen, Denmark. Available online at: http://ccafs.cgiar.org/resources/baseline-surveys

Egeru A (2012) Role of indigenous knowledge in climate change adaptation: a case study of the Teso SubRegion, Eastern Uganda. Indian J Tradit Knowl 11(2):217-224

Galacgac ES, Balisacan CM (2009) Traditional weather forecasting for sustainable agroforestry practices in Ilocos Norte Province, Philippines. For Ecol Manag 257:2044-2053

Intergovernmental Panel on Climate Change (IPCC) (2014) Working Group II AR5: Africa. In: Barros VR, Field CB, Dokken DJ, Mastrandrea MD, Mach KJ, Bilir TE, Chatterjee M, Ebi KL, Estrada YO, Genova RC, Girma B, Kissel ES, Levy AN, MacCracken S, Mastrandrea PR, White LL (eds) Climate Change 2014: Impacts, adaptation, and vulnerability. Part B: regional aspects. 36 contribution of working group II to the fifth assessment report of the Intergovernmental Panel on Climate Change. United Kingdom: Cambridge University Press. p 1199-1265

Joshua MK, Ngongondo C, Chipeta L, Mpembeka F (2011) Integrating indigenous knowledge with conventional science: enhancing localised climate and weather forecasts in Nessa, Mulanje, Malawi. Phys Chem Earth 36(2011):996-1003

Kadi M, Njau LN, Mwikya J, Kamga A (2011) The state of climate information services in East African countries. CCAFS working paper 5. Copenhagen, Denmark: Available online at: www.ccafs.cgiar.org

Kijazi AL, Chang'a LB, Liwenga ET, Kanemba A, Nindi SJ (2013) The use of indigenous knowledge in weather and climate prediction in Mahenge and Ismani wards, Tanzania. J Geogr Reg Plann 6(7):274-280

Kyazze FB, Kristjanson P (2011) Summary of baseline household survey results: Rakai district, south central Uganda. CGIAR Research Program on Climate Change, Agriculture and Food Security (CCAFS). Copenhagen, Denmark. Available online at: www.ccafs.cgiar.org

Lyamchai C, Yanda P, Sayula G, Kristjanson P (2011) Summary of baseline household survey results: Lushoto, Tanzania. CGIAR Research Program on Climate Change, Agriculture and Food Security (CCAFS). Copenhagen, Denmark. Available online at: www.ccafs.cgiar.org

Luseno W, McPeak J, Barrett C, Little P, Gebru G (2003) Assessing the value of climate forecast information for pastoralists: evidence from southern Ethiopia and northern Kenya. World Dev 31(9):1477-1494

Mahoo H, Mbungu W, Yonah I, Recha J, Radeny M, Kimeli P, Kinyangi J (2015) Integrating indigenous knowledge with scientific seasonal forecasts for climate risk management in Lushoto district in Tanzania. 
CCAFS Working Paper no. 103. CGIAR Research Program on Climate Change, Agriculture and Food Security (CCAFS). Copenhagen, Denmark. Available online at: www.ccafs.cgiar.org

Moran J, Morgan MD (1997) Meteorology: the atmosphere and the science of weather. Prentice Hall. Upper Saddle River, NJ 07458

Mubiru DN, Kristjanson P (2012) Summary of baseline household survey results: Hoima district, west central Uganda. CGIAR Research Program on Climate Change, Agriculture and Food Security (CCAFS). Copenhagen, Denmark. Available online at: www.ccafs.cgiar.org

Mubiru DN, Kyazze FB, Radeny M, Zziwa A, Lwasa J, Kinyangi J (2015) Climatic trends, risk perceptions and coping strategies of smallholder farmers in rural Uganda. CCAFS Working Paper no. 121. CGIAR Research Program on Climate Change, Agriculture and Food Security (CCAFS). Copenhagen, Denmark. Available online at: www.ccafs.cgiar.org

Nyong F, Adesina B, Osman E (2007) The value of indigenous knowledge in climate change mitigation and adaptation strategies in the African Sahel. Mitig Adapt Strat Glob Change 12(5):787-797

Orlove B, Roncoli C, Kabugo M, Majugu A (2010) Indigenous climate knowledge in southern Uganda: the multiple components of a dynamic regional system. Clim Chang 100(2):243-265

Osunade MA (1994) Indigenous climate knowledge and agricultural practices in Southwestern Nigeria. Malays J Trop Geogr 1:21-28

Risiro J, Mashoko D, Tshuma D, Rurinda E (2012) Weather forecasting and indigenous knowledge systems in Chimanimani District of Manicaland, Zimbabwe Journal of Emerging Trends in Educational Research and Policy Studies (JETERAPS) 3(4): 561-566

Speranza C, Kiteme B, Ambenje P, Wiesmann U, Makali S (2010) Indigenous knowledge related to climate variability and change: insights from droughts in semi-arid areas of former Makueni district, Kenya. Clim Chang 100(2):295-315

Ziervogel G, Opere A (eds) (2010) Integrating meteorological and indigenous knowledge-based seasonal climate forecasts in the agricultural sector. International Development Research Centre, Ottawa, Canada. Climate Change Adaptation in Africa learning paper series

Uganda Bureau of Statistics (UBOS)] (2015) Statistical abstract. UBOS, Kampala, Uganda

Publisher's note Springer Nature remains neutral with regard to jurisdictional claims in published maps and institutional affiliations.

\section{Affiliations}

\section{Maren Radeny ${ }^{1} \cdot$ Ayal Desalegn $^{2} \cdot$ Drake Mubiru $^{3} \cdot$ Florence Kyazze $^{4} \cdot$ Henry Mahoo $^{5}$. John Recha ${ }^{1} \cdot$ Philip Kimeli $^{6} \cdot$ Dawit Solomon $^{7}$}

1 CGIAR Research Program on Climate Change, Agriculture and Food Security Program, International Livestock Research Institute, Nairobi, Kenya

2 Center for Food Security Studies, Addis Ababa University, Addis Ababa, Ethiopia

3 Soils, Environment and Agro-Meteorology Unit, National Agricultural Research Laboratories, Kawanda, Uganda

4 College of Agricultural and Environmental Sciences, Makerere University, Kampala, Uganda

5 Department of Agricultural Engineering and Land Planning, Sokoine University of Agriculture, Morogoro, Tanzania

6 Rift Valley Water Works Development Agency, Nakuru, Kenya

7 CGIAR Research Program on Climate Change, Agriculture and Food Security Program, International Livestock Research Institute (ILRI), Addis Ababa, Ethiopia 